\title{
Transportes urbanos e o paradigma assegurado por políticas públicas
}

Urban transportation and the public policy paradigma

\author{
Danaê Fernandes* \\ Milena Kanashiro**
}

\begin{abstract}
Resumo
Após 7 anos da promulgação da Lei no 12.587/2012 instituindo a Política Nacional de Mobilidade Urbana brasileira (BRASIL, 2012), fez-se necessário refletir sobre os princípios legais que conformam os sistemas de transportes e, consequentemente, o espaço urbano. A partir de uma retrospectiva de temas que abordam o transporte coletivo e não motorizado, o presente trabalho analisa os esforços e as alterações de políticas públicas ocorridas nos últimos anos que acabaram por reforçar o automóvel como principal modo de deslocamento. Dessa maneira, a aplicação dos conceitos de justiça e equidade nos transportes é inviabilizada, de forma contrária aos fundamentos estabelecidos na Política Nacional de Mobilidade Urbana.
\end{abstract}

Palavras-chave: Mobilidade urbana. Pedestre. Bicicleta. Transporte público. Planejamento urbano.

\begin{abstract}
After seven years of the enactment of Law No. 12.587/ 2012 establishing the Brazilian National Urban Mobility Policy (BRASIL, 2012), it is necessary to reflect on the legal principles that shape the transport systems and, consequently, the urban space. Based on a retrospective of themes that address collective and non-motorized transportation, this paper analyzes the efforts and changes in public policies that have taken place in recent years that have reinforced the car as the main mode of travel. Thus, the application of the concepts of justice and fairness in transportation is unfeasible, contrary to the foundations established in the National Urban Mobility Policy.
\end{abstract}

Keywords: Urban mobility. Pedestrian. Bicycle. Public transportation. Urban planning.

\footnotetext{
* Mestrado em Arquitetura e Urbanismo pela Universidade Estadual de Londrina, especialista em engenharia de tráfego e planejamento de transportes.

** Doutorado em Meio Ambiente e Desenvolvimento/UFPR. Docente no Programa de Pós-Graduação em Arquitetura e Urbanismo UEL/UEM.

Agradecemos à CAPES pela concessão da bolsa de mestrado e à Fundação Araucária pela bolsa de pós doutorado.
} 


\section{Introdução}

A ascensão do automóvel, como modo de transporte principal, nas cidades é uma condição assumida internacionalmente de forma clara, ambientalmente predatória e isenta de responsabilidades sociais.

Para que este modo de transporte seja assimilado como dominante e desejável, é necessário dispor de suporte legal que estabeleça o predomínio automobilístico na mobilidade urbana, apesar dos constantes alardes sobre as consequências do uso extensivo de modos motorizados individuais de transporte, com impactos negativos no meio ambiente, saúde pública e equidade social (GUERRA; CUNHA, 2006).

Segundo Maricato (2014), o automóvel, que era uma opção para os mais ricos, passou a ser uma necessidade de todos, ao invés de escolha. A aparente liberdade de acesso a qualquer parte da cidade, a qualquer hora, quando estendida a grande parte da sociedade, interfere na qualidade urbana e promove uma ocupação esparsa e hostil aos movimentos de pedestres e ciclistas.

Com o aumento dos fluxos e das velocidades automotivas, ocorre um fenômeno conhecido como "efeito barreira", isto é, os modos motorizados se impõem fisicamente no território de forma a tornar impraticável ou insegura a circulação dos demais modos de transporte. Com isso, há a redução da interação social e do uso do espaço público, com consequências negativas cíclicas para toda a cidade (VASCONCELLOS, 2007).

Assim, os modos ativos de transporte, correspondendo ao modo a pé e por bicicleta, começam a ter suas possibilidades de transporte cada vez mais restritas e, como agravante, vivenciam as externalidades negativas produzidas pelo grupo motorizado.

As externalidades em sistemas de transportes, em sua definição, são os impactos causados por um modo de transporte sem que este esteja ciente do fato. No caso do transporte não motorizado, produz-se externalidades positivas no ambiente em geral, como a redução de poluentes e maior vitalidade urbana (JACOBS, 2000), com reverberação para todos os usuários dos sistemas de transportes.

Por outro lado, as principais externalidades dos transportes motorizados são a poluição atmosférica, congestionamento, acidentes, impermeabilização do solo, aumento dos tempos de viagem, espraiamento urbano, inequidade na distribuição de viagens por renda e todos os custos agregados, pagos por toda a sociedade (CASTRO, 2013). 
Quando analisados os efeitos da poluição e acidentes gerados pelos agentes motorizados, é consenso de que a maior intercorrência é sentida por pedestres e ciclistas, devido à ausência de proteção física aos choques e partículas poluidoras (FERNANDES; KANASHIRO, 2018).

Há indícios de que a formulação de políticas públicas voltadas ao planejamento urbano tem acentuado uma produção desigual do espaço urbano, já que algumas localidades são beneficiadas com maiores condições de deslocamentos, com modos de transportes mais rápidos e eficientes, enquanto outras áreas sofrem com sistemas de transportes deficitários.

No caso de deslocamentos insuficientes ou dificultados, tornam-se inacessíveis os atributos que a vida urbana oferece. Quando comprometido o acesso ao direito à cidade, é afetada a liberdade, a participação na sociedade e o usufruto de bens e oportunidades que deveriam ser de todos os cidadãos (LEFEBVRE, 2006).

Nesse sentido, além do transporte ser um direito social, garantido pela Emenda Constitucional no 90 de 2015, de iniciativa da deputada Luiza Erundina (BRASIL, 2015), é também o condutor do direito à cidade. Para que seja efetivado, é necessário suscitar discussões pautadas na desigualdade espacial como produto das infraestruturas de transportes, onde há consenso de que o principal responsável é o sistema baseado no automóvel, considerado uma alternativa de deslocamento de altos custos sociais, ambientais e econômicos, mas que provém de interesses industriais poderosos.

Em função da quantidade de veículos e da necessidade de conformar o espaço, o automóvel é responsável pelos impactos negativos mais persistentes na qualidade de vida urbana, e sua dominância entre os sistemas de transporte pode tornar os deslocamentos não motorizados desagradáveis e inseguros, além de diminuir a qualidade do transporte coletivo devido ao aumento de tempo e custo (VASCONCELLOS, 2007).

De acordo com Silva (2014), os modelos aplicados de ocupação do solo e parcelamento urbano são incompatíveis com a construção de uma mobilidade urbana sustentável e democrática. Nesse sentido, caberiam mudanças legislativas urgentes para romper tais modelos.

Para Shoup (2018), três decisões urbanísticas moldam um desenvolvimento urbano orientado ao automóvel e, portanto, espacialmente díspar: dividir o uso do solo em zonas, de forma a segregar moradia, emprego e comércio; limitar a densidade urbana, incentivando o 
espraiamento; e, por fim, decretar requisitos amplos de estacionamentos que garantam que o transporte automotivo seja o modo mais fácil e barato de deslocamento.

Com numerosos estudos e análises apontando a necessidade de reformulação da base dos sistemas de transportes brasileiros e ruptura do ciclo de dependência automobilística, foi aprovada a Política Nacional de Mobilidade Urbana, Lei no 12.587/2012 (BRASIL, 2012), após 17 anos de tramitação no Congresso.

Considerando que o prazo para a formulação dos Planos de Mobilidade Urbana para municípios com mais de 20 mil habitantes foi adiado para abril de 2019 pela Lei no 13.683/2018 (BRASIL, 2018a), considera-se oportuna a reflexão sobre as políticas públicas que moldam as condições urbanas de deslocamento, e suas implicações territoriais.

\section{A manutenção do espaço urbano orientado ao automóvel}

No Brasil, a indústria automobilística continua a ganhar a centralidade da preocupação de governos, com prioridade na concessão de subsídios (VASCONCELLOS, 2007), mesmo considerando que apenas $54 \%$ dos lares brasileiros possuem veículos motorizados (IBGE, 2016).

$\mathrm{Na}$ análise de 526 planos diretores municipais, promovida pelo Ministério das Cidades, considerando todos os estados e diferentes portes de municípios brasileiros (SANTOS JUNIOR; MONTANDON, 2011) explica-se parte do suporte dado à lógica individual motorizada do planejamento urbano pelo tratamento insuficiente direcionado ao transporte não motorizado (a pé e bicicleta). De forma desarticulada dos demais modos de transporte, muitas vezes o transporte não motorizado consta em planos diretores apenas como discurso ambiental sem aplicações específicas. Diferentemente das abordagens genéricas direcionadas aos pedestres e ciclistas, as temáticas viárias, como hierarquia e metas de pavimentação, possuem detalhamentos específicos e constam majoritariamente nos planos.

$\mathrm{O}$ fato de se direcionar o desenvolvimento da cidades orientado ao transporte individual motorizado exclui, por si só, cerca de metade da população brasileira, que não dispõe de automóvel ou motocicleta em sua residência.

No Brasil, os automóveis e motocicletas são responsáveis por $29 \%$ do total de viagens, mas respondem por $62 \%$ de toda energia consumida na mobilidade urbana, medida em TEP/ano, ou seja, toneladas equivalentes de petróleo (ANTP, 2018). Isso significa que os 
modos individuais motorizados respondem por $71 \%$ de toda a emissão de poluentes decorrente dos sistemas de transportes, considerando os poluentes locais monóxido de carbono, hidrocarbonetos, e óxidos de nitrogênio; o material particulado e os poluentes do efeito estufa.

Em medições de Black Carbon (BC), um dos poluentes atmosféricos mais nocivos à saúde humana e produzido por veículos motorizados, Targino et al. (2017) comprovam que pedestres e ciclistas recebem o maior teor de substância tóxica inalada, especialmente em vias de maior intensidade automotiva.

A produção de poluentes, assim como os acidentes de trânsito, são considerados externalidades do uso intensivo do transporte motorizado (GUERRA; CUNHA, 2006) e afetam, principalmente, aqueles que não participam dessa escolha de transporte. Pedestres e ciclistas são diretamente afetados, pois, ao contrário dos veículos motorizados, são desprovidos de qualquer tecnologia de filtragem de ar e defesa física contra colisões.

A realidade de $43 \%$ dos deslocamentos realizados no país é receber injustamente os poluentes e externalidades gerados por outros, já que essa é a porcentagem média de viagens diárias feitas a pé e por bicicleta. No caso de municípios com população inferior a um milhão de habitantes, esse percentual pode chegar a 51\% (ANTP, 2018).

Como contraste, recai sobre os $29 \%$ de viagens por transporte individual motorizado grande parte da poluição e acidentes. Os óbitos por transporte terrestre figuram entre as primeiras causas de óbitos por causas externas, em praticamente todas as faixas etárias (MACHADO FILHO, 2017), sendo a maior parte das vítimas pedestres e ciclistas, de menor renda (GWILLIAM, 2002).

A exposição dos usuários mais vulneráveis à poluição e acidentes, assim como o favorecimento automotivo no desenvolvimento urbano, são frequentemente assimilados à condição de custo inevitável do progresso, reforçado pela percepção da imprevisibilidade inerente aos acidente e expansão urbana. Desta forma, se estabelece como algo natural o aumento das externalidades negativas decorrentes do trânsito, assim como o incremento de velocidades e direcionamento de recursos crescentes para a manutenção desse sistema.

Essa aceitação do sistema de mobilidade baseado no automóvel só é possível por meio de políticas públicas, que carecem de contestações, de modo a criar condições sólidas 
para a mudança de paradigma de que os veículos motorizados são a única opção de deslocamento urbano eficiente (BLUE, 2013).

Se considerado o papel do transporte como um dos definidores da ocupação do solo, poderia se direcionar políticas públicas para um processo efetivo de planejamento de mobilidade urbana e, não apenas de transporte. Assim, torna-se necessário definir ferramentas para coibir a produção desigual do espaço urbano e a institucionalização de um sistema viário de baixa produtividade e de elevado custo de manutenção. Para tal reflexão, torna-se fundamental discutir os esforços políticos recentes.

\section{Adversidades nas políticas públicas de mobilidade humana}

A Política Nacional de Mobilidade Urbana, instituída pela Lei no 12.587/2012 (BRASIL, 2012), está fundamentada nos princípios de desenvolvimento sustentável, equidade de acesso e circulação, segurança, gestão democrática e controle social. De caráter inovador, estabelece a priorização de sistemas de transportes coletivos e não motorizados sobre os sistemas automotores. Entretanto, tal legislação foi moldada por sucessões de projetos de leis desde a Constituição Federal de 1988 (BRASIL, 1988), que definiu como competência da União o estabelecimento de diretrizes para os transportes urbanos.

Entre 1988 e a emenda constitucional de 2015, a qual incluiu o transporte como direito básico do cidadão (BRASIL, 2015), assim como a saúde, moradia, trabalho etc., foram pautados inúmeras propostas e projetos no intuito de assegurar a mobilidade urbana nas diferentes esferas governamentais.

Essa sucessão de projetos de leis que moldaram a Política Nacional de Mobilidade Urbana foi marcada por medidas consideradas contrárias aos princípios de desenvolvimento social e equidade social, inclusive por meio de vetos presidenciais. Na PL no 166/2010, conhecida como Lei da Mobilidade (BRASIL, 2010), houve o veto ao $§ 1$ do Artigo 8o, retirando o impedimento de subsídio cruzado pelos usuários de transporte público.

O subsídio cruzado é uma prática comum nas cidades brasileiras, onde o valor promocional pago por idosos, por exemplo, recai sobre os demais usuários pagantes, ao invés de ser custeado por subsídios diretos do Poder Público, como acontece nos países desenvolvidos (BAROUCHE, 2015). A prática do subsídio cruzado é considerada injusta aos usuários pagantes que têm de custear o sistema de transporte público (LIMA NETO; GALINDO, 
2015), já que no Brasil o serviço de transporte público por ônibus é custeado quase que exclusivamente pela arrecadação tarifária.

De acordo com Carvalho (2016), os mecanismos tarifários de transporte público atuais geram um círculo vicioso, em função do frequente aumento de tarifa e consequente perda de competitividade frente aos outros modos de transporte, retroalimentados pela perda de demanda.

Considerando os casos internacionais de sistemas de transporte público bem sucedidos são compostos por cerca de metade do orçamento advindo de subsídios, o Instituto de Pesquisa Econômica Aplicada-IPEA emitiu, em nota, que a linha de financiamento ideal para romper com o ciclo de decadência do transporte público brasileiro deveria contar com o uso do veículo individual motorizado como base de arrecadação, com a taxação do uso do espaço urbano, como a cobrança de estacionamentos públicos e pedágio urbano em áreas congestionadas (CARVALHO et al., 2013).

Nesse sentido, também houve veto presidencial ao Artigo $29^{\circ}$ da PL 694/1995 (BRASIL, 1995), que pautava a tarifa sobre congestionamento como possibilidade de reforço orçamentário do município para custear sistemas de transportes públicos urbanos.

Ainda assim, a Política Nacional de Mobilidade Urbana é considerada uma conquista, por entender a prioridade do transporte não motorizado e coletivo sobre os individuais motorizados, não só como regra de circulação, como consta no Código de Trânsito Brasileiro, a Lei no 9.503/1997 (BRASIL, 1997), mas também como primazia de recursos orçamentários e financiamentos.

Em análise de custos diretos de viagens com duração de $7 \mathrm{~km}$ feitas por motocicletas, veículos e transporte público, em 23 cidades grandes brasileiras, é possível visualizar (figura 1) o reflexo de políticas públicas vigentes nas tarifas de transportes. Para o cálculo, o custo direto do ônibus foi considerado o valor da tarifa, enquanto para automóveis e motocicletas foram estimados os gastos médios com combustível e estacionamento. Enquanto o custo direto de viagens por automóvel é geralmente inferior ao valor da tarifa de transporte público, quando feita pelo modo motocicleta corresponde a um quarto do preço da passagem. 


\section{Figura 1 - Média do custo direto de uso de ônibus, automóveis e motocicletas, em viagem de 7 km, em 23 grandes cidades do Brasil, no ano de 2014*}

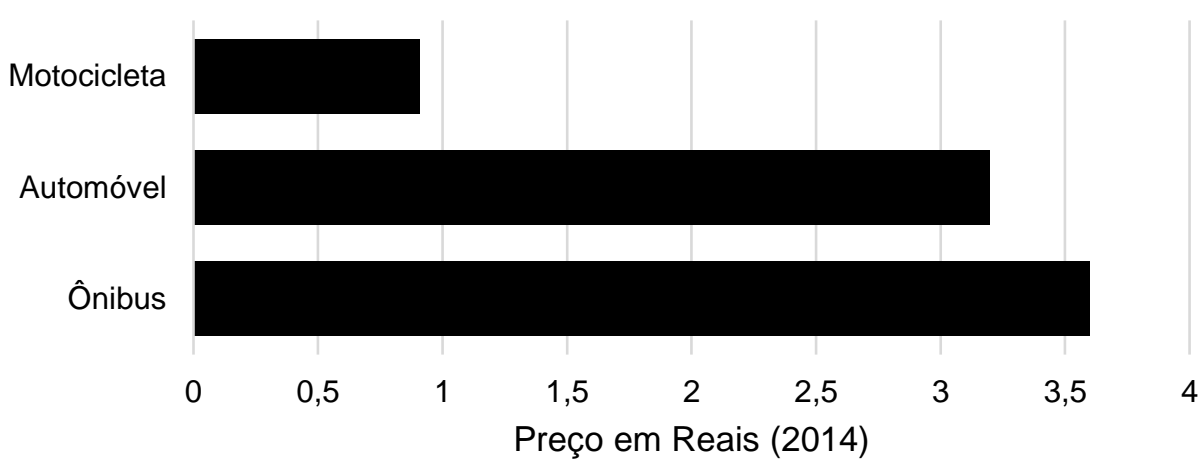

* Cidades consideradas: Belém, Belo Horizonte, Brasília, Campinas, Cuiabá, Curitiba, Feira de Santana, Florianópolis, Fortaleza, Goiânia, Guarulhos, Londrina, Manaus, Porto Alegre, Recife, Rio de Janeiro, Salvador, São Bernardo do Campo, São Gonçalo, São José dos Campos, São Paulo, Uberlândia e Vitória.

Fonte: ANTP (2017).

Percebe-se que a política de mobilidade leva à equalização de custos do transportes individuais motorizados, mesmo sendo estes responsáveis por maior consumo de espaço e infraestrutura públicos; maiores impactos ambientais, como uso de energia e poluição; e maiores custos sociais, decorrentes de acidentes, congestionamentos e diminuição de qualidade de vida (ANTP, 2017).

A exigência da inserção de critérios de equidade e democracia nos transportes, constante na Política Nacional de Mobilidade Urbana, deveria direcionar a alocação de recursos para maiores benefícios sociais, ao invés de privilegiar somente setores dominantes da sociedade que detém a posse dos veículos motorizados.

Com a aplicação do princípio de igualdade, na política e planejamento de transportes, seria urgente definir estratégias para que determinados tipos de transporte não seja impeditivo ao uso de outros, quer seja pela escolha ou possibilidade individual. Assim, tornaria-se natural e justificável a restrição a certos tipos de transporte que agem como barreira aos demais, pois uma pessoa não deveria minar as possibilidades de transporte de outras pela sua escolha ou possibilidade individual.

Aplicando-se princípios de igualdade na exposição ao risco nas barreiras enfrentadas pelo transporte ativo (a pé e de bicicleta), as restrições aos veículos motorizados são lógicas, envolvendo custos adicionais e limitações de uso e velocidade. 
Assim, deveria-se inserir uma responsabilidade social capaz de incentivar os modos ativos de transporte, com a formulação de princípios para sustentar políticas públicas voltadas ao acesso de oportunidades e atividades cotidianas por pedestres e ciclistas. Dessa forma, o transporte ativo não poderia ser encarado como um potencial para atingir certos benefícios, mas parte de um princípio moral fundamental para discutir políticas de planejamento e gestão urbana (MULLEN et al., 2014).

Todavia, a recente discussão acerca da Resolução 706 do Contran, que dispõe sobre o procedimento de autuação para pedestres e ciclistas, em âmbito nacional (CONTRAN, 2017), revelou o esforço punitivo das políticas públicas brasileiras, contrário ao incentivo do transporte ativo. Com a implementação da medida prevista para o ano de 2019, pedestres podem ser multados ao caminhar sobre a pista, realizar travessias fora da faixa demarcada, utilizar-se da via para esportes ou em agrupamentos capazes de perturbar o trânsito. Já os ciclistas, caso trafeguem na calçada, na mão contrária aos veículos, ou de forma agressiva.

Para especialistas, a medida apresenta obstáculos na fiscalização (LOBEL, 2017), além do fato de grande parte dos municípios brasileiros não oferecerem a infraestrutura mínima necessária para pedestres e ciclistas seguirem todas as normas de trânsito. Também é um alarde de que o movimento contemporâneo de apropriação da rua como espaço público de convívio não vem sendo adequadamente contemplado, quando não dificultado.

No Brasil, há uma tendência de crescimento de fatalidades em acidentes de transportes, especialmente entre os usuário mais vulneráveis, como pedestres e ciclistas (BID, 2013). Em consulta ao Painel Mobilidade Segura, a plataforma on-line onde a Prefeitura de São Paulo disponibiliza as autuações de trânsito registradas no município, é possível verificar que, do total de 3.317.149 autuações emitidas no ano de $2017,0,71 \%$ foram relacionadas à prática de "velocidades ameaçando pedestres e ciclistas" ou por "ameaçar ou deixar de dar preferência a pedestres e ciclistas" (SÃO PAULO, 2018).

Ainda na cidade de São Paulo, foi apresentado um procedimento de cálculo para abordar as iniquidades presentes nos sistemas de transportes conforme as diferentes classes de renda, conhecido como metabolismo da mobilidade (VASCONCELLOS, 2018). Levando-se em conta os acidentes causados, poluentes emitidos, energia consumida e as distâncias dinâmicas, ou seja, os quilômetros percorridos e a área ocupada pelo modo, por pessoa, conclui-se que os grupos de maior renda usam 8 vezes mais espaço que os grupos de menor 
renda, além de consumirem 9 vezes mais energia, emitirem 14 vezes mais poluentes e serem responsáveis por 15 vezes mais acidentes (figura 2 ):

Figura 2 - Metabolismo da mobilidade, cálculo pela cidade de São Paulo

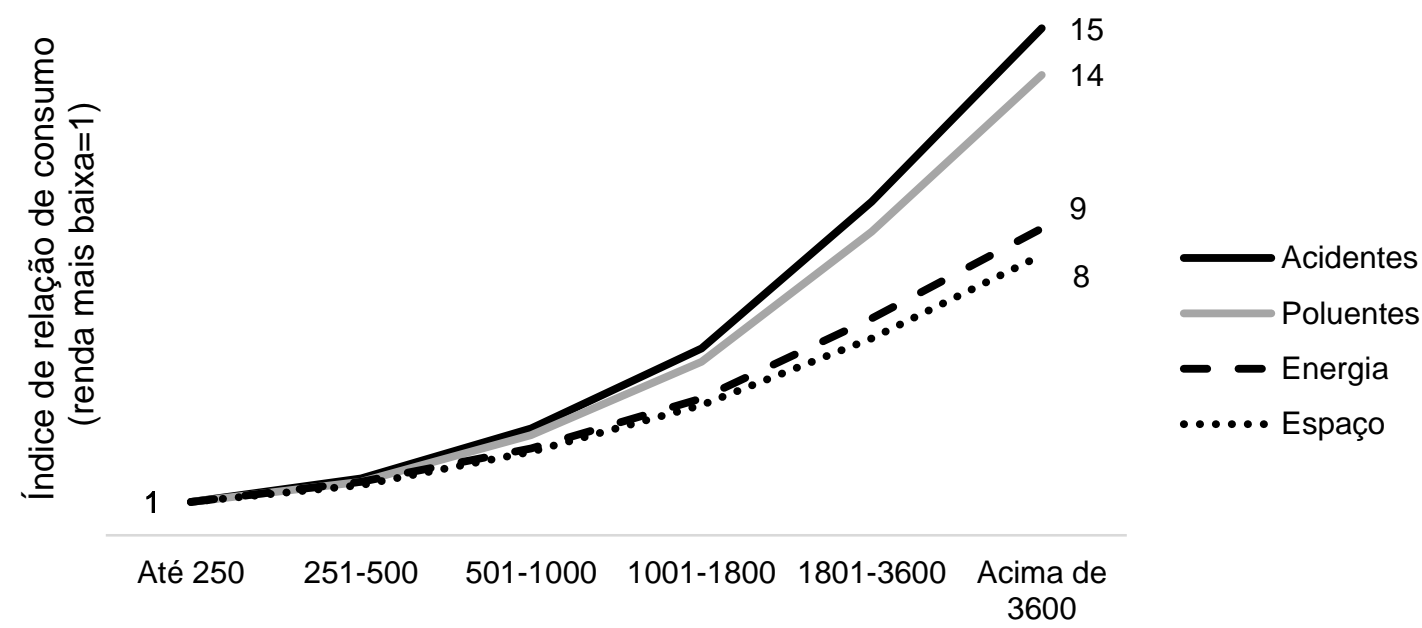

Renda familiar mensal $(\mathrm{R} \$)$

Fonte: Vasconcellos (2018).

Para clarificar a diferença de ocupação do espaço, a CET-Companhia de Engenharia de Tráfego de São Paulo, publicou dados de contagens de tráfego constatando que, nos horários de pico, 78\% das principais vias paulistanas são ocupadas por automóveis, transportando apenas $28 \%$ da população que opta pelo transporte motorizado. Enquanto isso, o transporte coletivo ocupa $8 \%$ da rede viária e carrega $68 \%$ desse total de pessoas (CORREA, 2012).

Entre as demonstrações de políticas públicas para o favorecimento do deslocamento automotivo, tem-se a PL 8837/2017 (BRASIL, 2017), que concede a gratuidade da carteira de habilitação $(\mathrm{CNH})$ a pessoas de baixa renda em todo território nacional, a exemplo de alguns estados como Rio Grande do Sul, São Paulo, Espírito Santo e Amazonas, que já subsidiam integralmente a emissão da carteira de motorista para cidadãos com renda familiar inferior a 3 salários mínimos.

Já a PL 11173/2018, propõe alteração no Código de Trânsito Brasileiro (BRASIL, 1997), ampliando de 20 para 50 pontos a suspensão do direito de dirigir, além de diminuir a pontuação das infrações, isentando assim as infrações de trânsito consideradas leves, como estacionar veículos sobre calçadas ou sobre faixa de travessia pedestre. Também ficam 
dispensados do cumprimento dos limites máximos de velocidade quaisquer veículos particulares em situação de urgência ou emergência.

Sob outra perspectiva, tem-se a Lei no 13.724/2018 (BRASIL, 2018b), que institui o Programa Bicicleta Brasil. Visando a melhorias sociais e ambientais, foi sancionada com veto presidencial a destinação de $15 \%$ do valor arrecadado com multas de trânsito ao programa. Assim, as opções de custeamento são doações ou repasse do CIDE, tributo federal regido pela Lei no 10.336/2001 (BRASIL, 2001) que, após seu repasse estadual, tem $25 \%$ de seu montante dividido entre os municípios, para programas de infraestrutura de transportes.

Infelizmente, não consta em lei nenhum percentual mínimo de destinação de verbas ao Programa Bicicleta Brasil, que pode não se realizar. Além disso, nada foi proferido em relação à redução de tributos incidentes sobre bicicletas e componentes. De acordo com a Associação Brasileira do Setor de Bicicletas (GUEDES FILHO et al., 2013), a tributação média incidente sobre bicicletas no país é de $63,1 \%$, percentual superior ao dos veículos (SILVA, 2010). O alto custo da tributação impacta no valor final do produto, que proporcionou uma demanda reprimida de população que não dispõe de recursos para a aquisição de equipamento.

Embora tenham ocorrido campanhas para a redução de imposto sobre produtos industrializados (IPI) para bicicletas, a PL 166/2009, que tinha esse objetivo, foi arquivada em 2014 (BRASIL, 2009).

\section{Conclusões}

Além de ser um direito em si e dar acesso aos outros direitos, a mobilidade urbana recebe o atributo fundamental de propiciar acesso à cidade.

Quando o uso dos veículos é analisado em relação às classes sociais, o uso do espaço mostra-se altamente desigual, sendo que aqueles com maior renda e posse de automóvel consomem mais espaço viário do que cidadãos que se deslocam a pé, de bicicleta ou transporte público.

Para considerar o acesso à cidade a todos, no seu sentido amplo, como uma condição possível de ser alcançada, identifica-se que o sistema baseado no uso intensivo do automóvel é uma barreira a ser moldada pela convivência com os demais modos de transporte. Assim, 
os sistemas de transporte podem contribuir para a redução da pobreza urbana, ou reforçá-la ainda mais.

Como um princípio democrático, devem-se incentivar esforços para tornar os sistemas de transporte mais justos, com propostas palpáveis para o desenvolvimento e melhoria dos transportes públicos e não motorizados.

Ademais, o envolvimento popular frente às propostas de continuidade do sistema de mobilidade vigente é crucial, tendo em vista as constantes formulações de propostas de leis que reforçam ainda mais o caráter automotivo das escolhas de transporte.

Diante da construção de um sistema viário baseado no automóvel, com baixa produtividade e elevado custo de manutenção, percebe-se que essa condição é sustentada por políticas públicas. Assim, qualquer tentativa de mudança de paradigma enfrentará obstáculos, inclusive envolvendo subsídios, vetos e discordâncias políticas.

Ainda que a mudança do enfoque automotivo esteja conceitualmente amparada pela Política Nacional de Mobilidade Urbana (Lei № 12.587), não existem garantias de mudanças concretas relacionadas à constante priorização do veículo individual motorizado no planejamento urbano. Por não dispor de mecanismos específicos que garantam sua aplicabilidade, nem a Política Nacional de Mobilidade Urbana nem o Programa Bicicleta Brasil traduzem-se, necessariamente, em políticas públicas efetivas.

Por meio da conformação de leis orientadas aos princípios de igualdade e democratização da mobilidade urbana, é delineado o apoio político ao transporte por automóvel através do tempo, onde as possibilidade de reversão desse sistema são retalhadas, como a tarifa sobre congestionamento, a destinação de verba relevante ao deslocamento por bicicleta e proibição da tarifa cruzada do transporte público.

Como definido por Oliveira Júnior (2012), a Política Nacional de Mobilidade Urbana é considerado um marco regulatório, mas também uma norma abstrata. Considera-se que sua composição normativa prática foi sendo diluída ao longo dos 17 anos em tramitação no Congresso, perdendo sua força de amplitude respaldada apenas em plano conceitual.

Ao mesmo tempo que se tornam conscientes da importância dos modos de transportes coletivos e não motorizados, continuam a impor legislações urbanísticas que asseguram a supremacia do planejamento urbano centrado no automóvel como modo dominante de transporte. 
É paradoxal, por exemplo, empenhar tantos esforços técnicos e políticos para escolher quais vias devem ser dotadas de ciclovias ou faixas exclusivas de ônibus, sem parar para refletir nas implicações da exigência maciça e inevitável de estacionamentos livres de tarifa, em áreas públicas, ou nas imposições urbanísticas dos requisitos mínimos de estacionamentos, estabelecidos nos Planos Diretores.

Também é um contrassenso o amparo legal à prática de subsídio cruzado tarifário nos sistemas de transporte público, garantindo que o custeio integral da viagem possa recair obre os usuários, enquanto continuam a serem implantadas políticas públicas de isenções sobre a utilização de veículos individuais motorizados, seja direta - como redução de tributos de combustíveis e veículos, ou indireta - tratando-se de facilidades para obtenção da carteira de motorista e a imposição de parâmetros urbanísticos de estacionamentos.

Conclui-se a urgência da discussão devido ao prazo final para a formulação de Planos de Mobilidade Urbana, fixado em abril de 2023, de forma a orientar políticas de transportes mais efetivas para a concretização do pleno acesso à cidade.

\section{Referências}

ANTP - ASSOCIAÇÃO NACIONAL DOS TRANSPORTES PÚBLICOS. Mobilidade humana para um Brasil urbano. São Paulo: ANTP, 2017.

ANTP - ASSOCIAÇÃO NACIONAL DOS TRANSPORTES PÚBLICOS. Sistemas de informações da mobilidade urbana: relatório geral 2016. São Paulo: ANTP, 2018.

BAROUCHE, Tônia de Oliveira. Tarifa social e subsídio cruzado: o mito da universalidade do transporte público brasileiro. 2015. 163 f. Dissertação (Mestrado em Direito) - Faculdade de Ciências Humanas e Sociais, Universidade Estadual Paulista, Franca, 2015.

BID - BANCO INTERAMERICANO DE DESENVOLVIMENTO. Avances em seguridad vial en América Latina y el Caribe 2010-2012. Washington: Asociación Española de la Carretera, 2013.

BLUE, Elly. Bikenomics: how bicycling can save the economy. Portland: Microcosm Publishing, 2013.

BRASIL. [Constituição (1988)]. Constituição da República Federativa do Brasil de 1988. Brasília: Presidência da República, 1988. Disponível em: http://www.planalto.gov.br/ccivil_03/constituicao/constituicao.htm. Acesso em: 1 jan. 2017. 
BRASIL. Emenda constitucional no 90, de 15 de setembro de 2015. Dá nova redação ao art. 60 da Constituição Federal, para introduzir o transporte como direito social. Brasília:

Presidência da República, 2015. Disponível em:

http://www.planalto.gov.br/ccivil_03/Constituicao/Emendas/Emc/emc90.htm. Acesso em: 1 mar. 2019.

BRASIL. Lei no 10.336, de 19 de dezembro de 2001. Institui Contribuição de Intervenção no Domínio Econômico incidente sobre a importação e a comercialização de petróleo e seus derivados, gás natural e seus derivados, e álcool etílico combustível (Cide), e dá outras providências. Brasília: Presidência da República, 2001. Disponível em: http://www.planalto.gov.br/CCivil_03/leis/LEIS_2001/L10336.htm. Acesso em: 1 mar. 2019.

BRASIL. Lei no 12.587, de 3 de janeiro de 2012. Institui as diretrizes da Política Nacional de Mobilidade Urbana; revoga dispositivos dos Decretos-Leis nos 3.326, de 3 de junho de 1941, e 5.405, de 13 de abril de 1943, da Consolidação das Leis do Trabalho (CLT), aprovada pelo Decreto-Lei no 5.452, de 10 de maio de 1943, e das Leis nos 5.917, de 10 de setembro de 1973, e 6.261, de 14 de novembro de 1975; e dá outras providências. Brasília: Presidência da República, 2012. Disponível em: http://www.planalto.gov.br/ccivil_03/_Ato20112014/2012/Lei/L12587.htm. Acesso em: 1 mar. 2019.

BRASIL. Lei no 13.683, de 19 de junho de 2018. Altera as Leis nos 13.089, de 12 de janeiro de 2015 (Estatuto da Metrópole), e 12.587, de 3 de janeiro de 2012, que institui as diretrizes da Política Nacional de Mobilidade Urbana. Brasília: Presidência da República, 2018a. Disponível em: http://www.planalto.gov.br/ccivil_03/_Ato2015-2018/2018/Lei/L13683.htm. Acesso em: 1 mar. 2019.

BRASIL. Lei no 13.724, de 4 de outubro de 2018. Institui o Programa Bicicleta Brasil (PBB) para incentivar o uso da bicicleta visando à melhoria das condições de mobilidade urbana. Brasília: Presidência da República, 2018b. Disponível em: http://www.planalto.gov.br/ccivil_03/_Ato2015-2018/2018/Lei/L13724.htm. Acesso em: 1 mar. 2019.

BRASIL. Lei no 9.503, de 23 de setembro de 1997. Institui o Código de Trânsito Brasileiro. Brasília: Presidência da República, 1997. Disponível em: http://www.planalto.gov.br/ccivil_03/LEIS/L9503.htm. Acesso em: 1 mar. 2019.

BRASIL. Projeto de lei da Câmara no 166, de 2010. Institui as diretrizes da Política Nacional de Mobilidade Urbana; revoga dispositivos dos Decretos-Leis no s 3.326, de 3 de junho de 1941, e 5.405, de 13 de abril de 1943, da Consolidação das Leis do Trabalho - CLT, aprovada pelo Decreto-Lei $n$ o 5.452, de $1^{\circ}$ de maio de 1943, e das Leis $n$ 오 5.917, de 10 de setembro de 1973, e 6.261, de 14 de novembro de 1975; e dá outras providências. Brasília: Câmara dos Deputados, 2010. Disponível em: https://www25.senado.leg.br/web/atividade/materias//materia/97805. Acesso em: 1 mar. 2019.

BRASIL. Projeto de lei do Senado no 166, de 2009. Concede isenção do Imposto sobre Produtos Industrializados incidente sobre bicicletas, suas partes e peças, e reduz a zero as alíquotas da Contribuição para o PIS/PASEP e da Contribuição para o Financiamento da Seguridade Social incidentes sobre a importação e a receita bruta decorrente da venda, no 
mercado interno, desses bens. Brasília: Senado Federal, 2009. Disponível em: https://www25.senado.leg.br/web/atividade/materias/-/materia/90815. Acesso em: 1 mar. 2019.

BRASIL. Projeto de lei no 694, de 29 de junho de 1995. Institui as diretrizes nacionais do transporte coletivo urbano e dá outras providências. Brasília: Câmara dos Deputados, 1995. Disponível em:

https://www.camara.leg.br/proposicoesWeb/fichadetramitacao?idProposicao=15750. Acesso em: 1 mar. 2019.

BRASIL. Projeto de lei no 8.837, de 11 de novembro de 2017. Acrescenta dispositivo à Lei 9.503, de 1997, Código de Trânsito Nacional para instituir o Programa Carteira Nacional de Habilitação Social - CNH Social. Brasília: Câmara dos Deputados, 2017. Disponível em: https://www.camara.leg.br/proposicoesWeb/fichadetramitacao idProposicao=2155859. Acesso em: 1 mar. 2019.

CARVALHO, Carlos Henrique Ribeiro de. Aspectos regulatórios e conceituais das políticas tarifárias dos sistemas de transporte público urbano no Brasil. Texto para Discussão, Brasília, n. 2192, abr. 2016.

CARVALHO, Carlos Henrique Ribeiro de; GOMIDE, Alexandre; PEREIRA, Rafael Henrique Moraes; MATION, Lucas Ferreira; BALBIM, Renato; LIMA NETO, Vicente Correia; GALINDO, Ernesto Pereira; KRAUSE, Cleandro; GUEDES, Erivelton Pires. Tarifação e financiamento de transporte público urbano. Brasília: IPEA, 2013. (Nota Técnica, n. 2).

CASTRO, Newton de. Mensuração de externalidades do transporte de cargas brasileiro. Journal of Transport Literature, Manaus, v. 7, n. 1, p. 163-181, jan. 2013.

CONTRAN. Resolução no 706, de 25 de outubro de 2017. Dispõe sobre a padronização dos procedimentos administrativos na lavratura de auto de infração, na expedição de notificação de autuação e de notificação de penalidades por infrações de responsabilidade de pedestres e de ciclistas, expressamente mencionadas no Código de Trânsito Brasileiro. Diário Oficial da União: seção 1, Brasília, n. 207, p. 92, 27 out. 2017.

CORREA, Vanessa. Carro toma quase toda a rua sem transportar nem 1/3 dos paulistanos. Folha de S. Paulo, São Paulo, 12 ago. 2012. Disponível em:

https://www1.folha.uol.com.br/saopaulo/2012/08/1135249-carro-toma-quase-toda-a-ruasem-transportar-nem-13-dos-paulistanos.shtml. Acesso em: 24 fev. 2019.

FERNANDES, Danaê; KANASHIRO, Milena. A bicicleta como componente da justiça dos transportes. In: COLÓQUIO IBÉRICO DE GEOGRAFIA, 16., 2018, Lisboa. Anais [...]. Lisboa: IGOT, 2018. p. 237-246.

GUEDES FILHO, Ernesto Moreira; CURI, Andréa Zaitune; RIBEIRO, Fernanda; CONDE, Rayane; ROSSI, Carla. Análise econômica do setor de bicicletas e suas regras tributárias. São Paulo: Tendências Consultoria Integrada, 2013.

GUERRA, Antonio José Teixeira; CUNHA, Sandra Baptista da (org.). Impactos ambientais urbanos no Brasil. 4. ed. Rio de Janeiro: Bertrand Brasil, 2006. 
GWILLIAM, Kenneth M. Cities on the move: a World Bank urban transport strategy review. Washington: The World Bank, 2002.

IBGE. Pesquisa nacional por amostra de domicílios - PNAD: síntese dos indicadores. Rio de Janeiro: IBGE, 2016.

JACOBS, Jane. Morte e vida de grandes cidades. São Paulo: Martins Fontes, 2000.

LEFEBVRE, Henri. O direito à cidade. 6. ed. São Paulo: Centauro, 2006.

LIMA NETO, Vicente Correia; GALINDO, Ernesto Pereira. Planos de mobilidade urbana: instrumento efetivo da política pública de mobilidade? Texto para Discussão, Rio de Janeiro, n. 2115, ago. 2015.

LOBEL, Fabrício. Multa a pedestres e ciclistas podem virar letra morta, dizem especialistas. Folha de S. Paulo, São Paulo, 28 out. 2017. Disponível em: https://www1.folha.uol.com.br/cotidiano/2017/10/1931071-multas-a-pedestres-e-ciclistaspodem-virar-letra-morta-dizem-especialistas.shtml. Acesso em: 23 fev. 2019.

MACHADO FILHO, Haroldo (org.). Objetivos de desenvolvimento sustentável. Documentos Temáticos das Nações Unidas no Brasil. Brasília: ONU, 2017.

MARICATO, Erminia. O impasse da política urbana no Brasil. 3. ed. Petrópolis: Vozes, 2014.

MULLEN, Caroline; TIGHT, Miles; WHITEING, Anthony; JOPSON, Ann. Knowing their place on the roads: what would equality mean for walking and cycling? Transportation Research Part A: Policy and Practice, Oxford, v. 61, p. 238-248, Mar. 2014.

OLIVEIRA JÚNIOR, João Alencar. Princípios, diretrizes e objetivos da Lei no 12.587/2012: por um pacto social em prol da mobilidade urbana. Revista UFG, Goiânia, v. 13, n. 12, p. 18-27, jul. 2012.

SANTOS JUNIOR, Orlando Alves dos; MONTANDON, Daniel Todtmann (org.). Planos diretores municipais pós-estatuto da cidade: balanço crítico e perspectivas. Rio de Janeiro: Letra Capital, 2011.

SÃO PAULO. Prefeitura. Painel mobilidade segura. São Paulo: Prefeitura Municipal, 2018. Disponível em:

http://mobilidadesegura.prefeitura.sp.gov.br/QvAJAXZfc/opendoc.htm?document=Painel_ Mobilidade_Segura.qvw\&host=QVS\%40c65v27i\&anonymous=true. Acesso em: 22 fev. 2018.

SHOUP, Donald. Parking and the city. New York: Routledge, 2018.

SILVA, Eduardo Fernandez. Automóveis, preços e tributos: Brasil e outros países. Brasília: Câmara dos Deputados, 2010.

SILVA, Eduardo Fernandez. Meio ambiente \& mobilidade urbana. São Paulo: Editora Senac, 2014. 
TARGINO, Admir Créso; RODRIGUES, Marcos Vinicius C.; KRECL, Patricia; CIPOLI, Yago Alonso; RIBEIRO, João Paulo M. Commuter exposure to black carbon particles on diesel buses, on bicycles and on foot: a case study in a Brazilian city. Environmental Science Pollution Research, Exeter, v. 25, p. 1132-1146, 2018.

VASCONCELLOS, Eduardo Alcântara de. Transporte e meio ambiente: conceitos e informações para análise de impactos. São Paulo: Annablume, 2007.

VASCONCELLOS, Eduardo Alcântara de. Urban transport policies in Brazil: the creation of a discriminatory mobility system. Journal of Transport Geography, Amsterdam, v. 67, p. 85-91, 2018. 